Querschnitt eines durch Stammzellen entstandenen Mäusegehirntumors: die histologischen Merkmale des Tumors ähneln auffallend einem menschlichen Gehirntumor.

\title{
Signalweg hemmt Entwicklung von Hirntumoren
}

\begin{abstract}
Biomediziner der Universität Basel haben sich einen weitverbreiteten Signalweg genauer angesehen und festgestellt, dass er die Entwicklung gewisser Hirntumorarten unterdrückt. Die Resultate wurden in der Fachzeitschrift Cancer Cell veröffentlicht. Gliome sind die häufigste Art von Hirntumoren bei Erwachsenen, die Prognose für die Betroffenen ist meist sehr schlecht. Neue und effektivere Therapien sind dringend notwendig. Um diese zu entwickeln, ist es wichtig, die Biologie der Erstehung diese Tumore besser zu verstehen.
\end{abstract}

\section{Stammzellen als mögliche Tumorursache \\ Bisher ist nicht klar, welche Zellen Gliome verursachen können wenn Gene mutiert sind. Forscher vermuten, dass Hirnstamm- zellen ein möglicher Ursprung von Hirntumoren sein könnten. Stammzellen des menschlichen Gehirns können neue Nerven- zellen bilden; läuft in diesem Vorgang etwas schief und kommt es zu unkontrollierter Zellvermehrung oder gestörter Zelldiffe- renzierung, könnte das einen Hirntumor entstehen lassen. Ein Forschungsteam um Prof. Verdon Taylor vom Departement Bio- medizin der Universität Basel hat nun in einer Studie unter- sucht, ob der Mechanismus, welcher die Stammzellerhaltung im Gehirn regelt, möglicherweise von Krebszellen zur Bildung von Tumoren sozusagen missbraucht wird.}

\section{Aktiver Signalweg unterdrückt Tumorbildung}

Die Forscher untersuchten den sogenannten Notch-Signalweg. Dieser ist zentral für die Stammzellenaktivität im Gehirn, und es wird vermutet, dass er - einmal aktiviert - zum Wachstum von Hirntumoren führen kann. «Entgegen unserer Erwartun- gen haben wir aber festgestellt, dass das genaue Gegenteil der Fall ist: die Aktivierung dieses Signalweges unterdrückt die Entwicklung von bestimmten Hirntumorarten sogar», sagt Claudio Giachino, Erstautor der Studie. Umgekehrt liess die Stilllegung des Signalwegs gewisse Arten von Gliomen aggressiver werden und schneller wachsen.

Aufgrund dieser Eigenschaft könnte der Notch-Signalweg in Zukunft einerseits zum Ziel neuer Therapieansätze werden und andererseits als Diagnoseinstrument dienen, um verlässlichere Prognosen für Patienten zu erstellen. «Unsere Resultate zeigen auch, dass grosse Unterschiede in den molekularen Signalwegen zwischen vordergründig ähnlichen Hirntumorarten bestehen. In Zukunft sollte die Art des Glioms viel genauer untersucht werden, bevor eine spezifische Therapie angewendet wird», so Taylor.

Quelle: Claudio Giachino, et al: A Tumor Suppressor Function for Notch Signaling in Forebrain Tumor Subtypes Cancer Cell (2015), doi: 10.1016/j.ccell.2015.10.008 